\title{
Maternal comprehension of two growth monitoring charts in Sri Lanka
}

\author{
Manouri P Senanayake, M K S Gunawardena, D S P Peiris
}

\begin{abstract}
Objective-To investigate the maternal comprehension of two different growth charts and to identify the group of mothers with poor comprehension.

Design-An experimental prospective study.

Setting-A child welfare clinic at the De Soysa Hospital for Women, Colombo, Sri Lanka.

Subjects-932 mothers were studied regarding their interpretation of the type of growth chart their infants had been allocated. A total of $\mathbf{4 1 3}$ mothers interpreted the 'road-to-health' chart and 519 mothers interpreted the revised chart. A validated scoring system was used to assess comprehension. The two groups of mothers were comparable.

Results-62.4\% (324) mothers who interpreted the revised chart had good comprehension. Only $20.6 \%$ (85) mothers had similar comprehension with the road-tohealth chart. Education up to or beyond grade 8 in school significantly improved comprehension.

Conclusion-The design of the growth chart has a powerful effect on maternal comprehension of growth patterns. Length of schooling rather than literacy alone is a marker of a comprehending mother. The policy implications of these findings are that governments and agencies may need to redesign parent held growth charts to achieve better comprehension by mothers.

(Arch Dis Child 1997;76:359-361)
\end{abstract}

Keywords: maternal comprehension; growth monitoring charts; nutrition

Growth monitoring charts are expected to function as educational tools whereby mothers gain knowledge of growth, nutrition, and the consequence of illness on growth. The format of growth charts and their suitability has been under discussion. ${ }^{12}$ Clinical utility and ease of interpretation are two important factors considered in choosing a growth chart.

In 1994, the World Health Organisation (WHO) 'road-to-health' growth chart (fig 1) in the parent held child health development record used in Sri Lanka was replaced with a revised edition (fig 2 ). The redesigned growth chart has a set of coloured and shaded curves. These curves do not correspond to specific centiles but portray in colour the area delimited by the 50 th centile for boys and 3 rd centile for girls of the American National Center for Health Statistics (NCHS) standards.

Since maternal involvement would depend on knowledge, studies have been carried out to assess maternal comprehension of growth monitoring charts. ${ }^{3-5}$ The effect of literacy on comprehension of anthropometry has shown varying results. ${ }^{56}$ Sri Lanka has a female literacy rate of $82.3 \%$ with higher rates in the urban areas. ${ }^{7}$

This study compares the two growth monitoring charts used in Sri Lanka, with regard to maternal comprehension. Mothers with poor comprehension were studied to identify a target group needing greater instruction about growth monitoring charts.

\section{Subjects and methods}

STUDY SAMPLE

A total of 932 mothers, each with a child under the age of 13 months, formed the study population. The study was carried out during the transition period when both types of charts were in use among the clinic attenders. The selection of infants for allocation of the different growth charts was according to availability and without bias.

All mothers who had attended the child welfare clinic at the De Soysa Hospital for Women Colombo on three or more occasions were enrolled into two groups, according to the type of growth chart assigned to each infant.

\section{STUDY DESIGN}

The evaluation of comprehension was based on the format of a previous study carried out in north east Brazil. ${ }^{5}$ Five sets of growth curves that depict different nutritional situations of fictitious children aged 6 months to 18 months (fig $3 \mathrm{~A}-\mathrm{E}$ ) were plotted on real charts of the type assigned to each mother's baby.

Informed consent was obtained and the mothers were classified as literate or illiterate by testing their ability to read 'Mother, your milk is best for your baby' written in Sinhala or Tamil. Maternal age, ethnic group, birth order of child, and the level of education were recorded.

The interpretation of the five sets of growth charts was judged correct, incorrect, or uncertain and a score ranging from $0-5$ was awarded based on one point for each correct answer and zero for each incorrect or uncertain answer. The responses rated as correct are stated in fig $3(\mathrm{~A}-\mathrm{E})$. Scores of $0-2$ were considered 'poor comprehension', a score of 3 'satisfactory comprehension', and 4 or 5 'good comprehension'.

Mothers who had poor comprehension with the revised chart were studied in detail. 


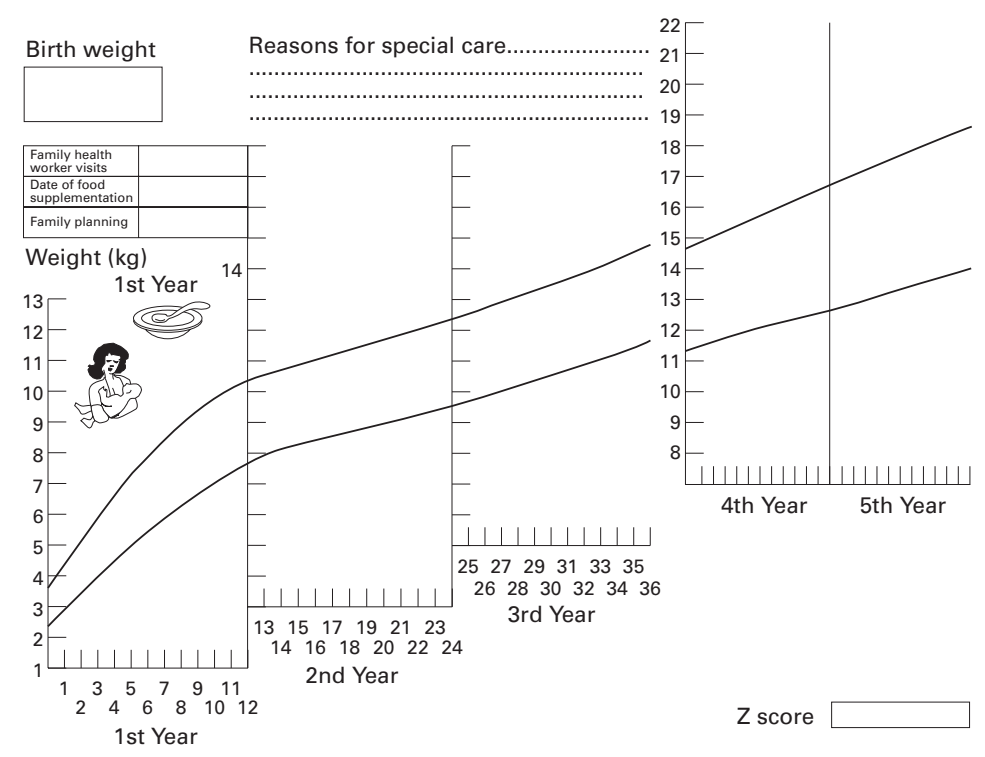

Figure 1 Road-to-health chart (simplified and translated).

\section{Results}

A total of 932 mothers were interviewed; 413 mothers interpreted the road-to-health chart and 519 mothers interpreted the revised chart. Both groups of mothers were of similar socioeconomic status and literacy levels.

The relevant demographic characteristics are shown in table 1 . The comprehension scores obtained with the two groups of mothers are shown in table 2 . Two hundred and fifty two $(27 \%)$ of 932 mothers were found to have comprehension scores of $0-2$, despite the study sample having a literacy rate of $95 \%$.

Altogether $62.4 \%$ (324) of mothers had 'good comprehension' with the revised chart while only $20.6 \%$ (85) had similar results with the road-to-health chart. This difference is statistically significant $(\mathrm{p}<0.001)$.

Characteristics of mothers who interpreted the revised chart are shown in table 3. Mothers whose educational level had not reached grade 8 in school were found to have poorer comprehension compared with those educated up to or beyond grade 8 .

\section{Discussion}

The involvement of mothers in the health care of their babies is a desired consequence of growth monitoring. Easy interpretation and good understanding of growth monitoring charts by mothers is necessary to achieve this objective.

This study compared the effectiveness of two different forms of growth charts regarding their educational value. The road-to-health chart was compared with a revised edition among mothers of similar socioeconomic status and literacy levels. There was no bias in allocation of mothers to the two charts. Clinic variations and differing educational inputs that would affect the validity of the data did not occur.

The population studied comprised urban mothers of lower socioeconomic groups. Approximately $95 \%$ of mothers were literate and $5 \%$ were illiterate.

The revised chart was significantly better understood than the road-to-health chart. Difficulties in comprehending the road-to-health chart have been previously reported in India. ${ }^{8}$ The redesigned chart caused the percentage of mothers with comprehension scores of 4 and 5 to increase from $20.6 \%$ to $62.4 \%$. The direction of normal growth being depicted by a series of bands rather than with two centile lines only, would have resulted in the observed improvement in comprehension. This finding suggests the need for governments and agencies to redesign growth charts to improve comprehension.

In the total study sample comprehension scores were found to be low (0-2) in $27.0 \%$ (252) of mothers. The effect of maternal literacy on comprehension of growth charts has remained unclear. Grant and Stone found that literate mothers in Afghanistan had better comprehension than illiterate mothers. ${ }^{3}$ Ruel et $a l$ and McAuliffe et al in studies carried out in Lesotho and north east Brazil respectively concluded that illiterate mothers could understand 

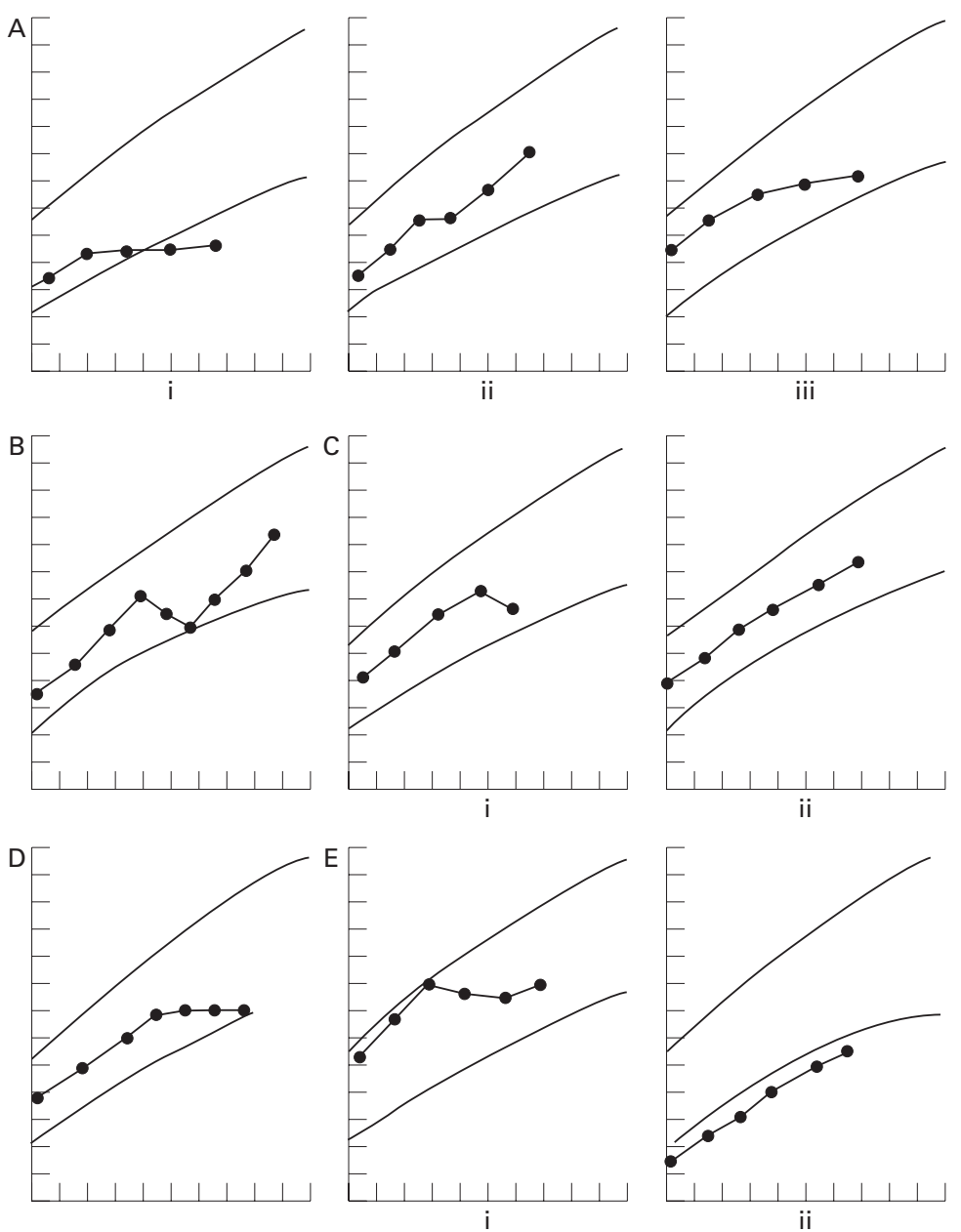

Figure 3 Five sets of sample growth charts $(A-E)$ with individual captions and correct responses. (A)The ability to recognise the chart showing the best growth from three sample growth curves (correct response: chart (ii)). (B) Ability to identify a point on a growth curve where a significant health problem occurred (correct response: dip in curve). (C) Ability to recognise the growth curve reflecting the impact of diarrhoea (correct response: chart (i)). (D) Ability to interpret correctly a curve showing no weight gain (correct response: stationary weight or absence of weight gain). (E) Ability to distinguish between adequate growth below the bottom line (3rd centile) and inadequate weight gain between the top and bottom (3rd and 50th) centile lines (correct response: chart (i), inadequate growth; chart (ii), adequate growth).

Table 1 Demographic characteristics of the two groups of mothers interpreting different growth charts; values are number (\%)

\begin{tabular}{|c|c|c|}
\hline & Road-to-health chart $(n=413)$ & Revised chart $(n=519)$ \\
\hline \multicolumn{3}{|l|}{ Ethnicity } \\
\hline Sinhala & $350(84.7)$ & $430(82.9)$ \\
\hline \multicolumn{3}{|l|}{ Maternal age (years) } \\
\hline$<20$ & $18(4.4)$ & $27(5.2)$ \\
\hline $21-35$ & $379(91.8)$ & $470(90.0)$ \\
\hline \multicolumn{3}{|l|}{ Birth order } \\
\hline 1st child & $180(43.6)$ & $236(45.7)$ \\
\hline$\geqslant 3$ children & $61(14.7)$ & $69(13.2)$ \\
\hline \multicolumn{3}{|l|}{ Educational status } \\
\hline Illiterate & $23(5.6)$ & $24(4.6)$ \\
\hline Up to grade 8 & $110(20.6)$ & $106(20.4)$ \\
\hline Grade 10 and over & $115(27.8)$ & $168(32.3)$ \\
\hline
\end{tabular}

growth monitoring charts after instructions were given. ${ }^{45}$

This study shows that difficulties in comprehension of growth charts were present despite literacy. The ability to comprehend graphic representations of weight is probably not related to literacy, defined as the ability to read
Table 2 Comprehension scores of the two groups of mothers; values are number (\%)

\begin{tabular}{lll}
\hline & $\begin{array}{l}\text { Road-to-health chart } \\
(n=413)\end{array}$ & $\begin{array}{l}\text { Revised chart } \\
(n=519)\end{array}$ \\
\hline $\begin{array}{l}\text { Poor comprehension } \\
\quad(\text { score 0-2) }\end{array}$ & $166(40.2)$ & $86(16.6)$ \\
$\begin{array}{l}\text { Satisfactory } \\
\text { comprehension } \\
\text { (score 3) }\end{array}$ & $162(39.2)$ & $109(21.0)$ \\
$\begin{array}{l}\text { Good comprehension } \\
(\text { score 4 or 5) }\end{array}$ & $85(20.6)$ & $324(62.4)$ \\
\hline
\end{tabular}

Table 3 Characteristics of mothers who interpreted the revised growth chart

\begin{tabular}{llll}
\hline & $\begin{array}{l}\text { Poor } \\
\text { comprehension: } \\
\text { score 0-2 } \\
(n=86)\end{array}$ & $\begin{array}{l}\text { Good } \\
\text { comprehension: } \\
\text { score 4 or 5 } \\
(n=324)\end{array}$ & $\begin{array}{l}\text { Significance } \\
(p \text { value })\end{array}$ \\
\hline $\begin{array}{c}\text { Mean (SD) } \\
\text { maternal age } \\
\text { (years) }\end{array}$ & $27.0(5.69)$ & $28.6(4.6)$ & $<0.05$ \\
$\begin{array}{c}\text { Level of education } \\
\geqslant \text { grade 8 }(\%)\end{array}$ & $39(45.3)$ & $292(90)$ & $<0.05$ \\
$\begin{array}{c}\text { Birth order } \geqslant 3 \\
(\%)\end{array}$ & $13(15)$ & $37(11)$ & $>0.05$ \\
\hline
\end{tabular}

at least one language. Detailed analysis of the educational levels of mothers who interpreted the revised chart showed that education beyond grade 8 in school significantly improved interpretation of growth charts.

Mothers with good comprehension were significantly older than mothers with poor comprehension (table 3). The significant difference in maternal age is perhaps due to higher educational levels being associated with a delay in childbearing.

We conclude that length of schooling rather than literacy was a marker of comprehension. This may explain why growth monitoring has had a variable impact on maternal comprehension in different settings.

Literacy alone is not sufficient to comprehend growth charts. Secondary school education for girls improves comprehension significantly. Further, changing the format of the chart itself can contribute significantly to ease of interpretation and better comprehension. Hence we have established the need to redesign growth charts to enhance their educational value.

1 Cole TJ. Do growth chart centiles need a facelift? $B M F$ 1994;308:641-2.

2 Voss LD, Wilkin TJ, Betts PR. Do we need new growth charts? Lancet 1987;ii:447-8.

3 Grant K, Stone T. Maternal comprehension of a homebased growth chart and its effect on growth. 7 Trop Pediatr 1986;32:255-7.

4 Ruel MT, Pelletier DL, Habicht JP, Mason JB, Chobohoare CS, Marnping AP. Comparison of mothers understanding of two child growth charts in Lesotho. World Health Bulletin

5 McAuliffe JF, Falcao L, Duncan B. Understanding of McAuliffe JF, Falcao L, Duncan B. Understanding of
growth monitoring charts by literate and illiterate mothers in north east Brazil. F Trop Pediatr 1993;39:370-2.

6 Gopalan C, Chatterjee M. Use of growth charts for promoting child nutrition - a review of global experience. Special publication series 2. New Delhi: Nutrition Foundation of India, 1985.

7 Ministry of Health. Annual health bulletin. Colombo, Sri Lanka: Ministry of Health, 1992:7.

8 Gopaldas T. Field-level health worker's skill in detection of growth retardation and faltering in young children. Indian $\mathcal{F}$ 